\section{Atopisches Ekzem}

\section{Ist unsere Ernährung schuld?}

\author{
Von der atopischen Dermatitis (AD) sind schätzungsweise 10-15\% \\ der Bevölkerung in Industrieländern betroffen. Bei Kindern mit AD \\ kann die Ursache in ca. 30\% der Fälle auf nachgewiesene \\ Nahrungsmittelallergien zurückgeführt werden. 2-7\% der \\ betroffenen Kinder zeigen außerdem pseudo-allergische \\ Reaktionen auf Nahrungsmittelzusätze.
}

Dseuction seudo-allergene Nahrungsmittelzusätze wie Farb- und Konservierungsstoffe, Sulphite, Benzoesäure, Glutamat u.a. stehen im Verdacht, neben Nahrungsmittelallergenen Auslöser der AD zu sein. Im Gegensatz zur „klassischen“, T-Zell vermittelten Typ-I-Allergie ist der Zusammenhang zwischen Agenz und Reaktion bei pseudo-allergischer Sensitivität weniger gut definiert. Die hypersensitive Antwort auf Pseudo-allergene ist nicht IgE-vermittelt und erfordert keine vorherige Sensibilisierung. Stattdessen nimmt man an, dass Pseudo-allergene über eine direkte Aktivierung von Mastzellen die Ausschüttung von Histamine, Tryptase und anderen proinflammatorischen Mediatoren bewirken.

In einer Studie der Berliner Humboldt Universität wurde nun die Beteiligung von Nahrungsmittelzusätzen an der AD bei Erwachsenen untersucht. 41 Patienten im Alter von 18-72 Jahren beteiligten sich an einer dreiphasigen Studie: In Phase I wurden die Patienten über 4 Wochen beobachtet - bei allen wurde die $\mathrm{AD}$ mit einem so genannten Costa-Wert quantifiziert. Phase II bestand aus einer 6-wöchigen Diät frei von gängigen Allergenen und ohne oder mit nur sehr geringen - Nahrungsmittelzusätzen. Früchte, Süßwaren, Eier, die meisten Gewürze, Margarine und Mayonnaise, Fisch und geräuchertes Fleisch, Pilze, Tomaten, Oliven, Spinat, Paprika und andere Gemüse, viele Milchprodukte, sowie alle gefärbten Nahrungsmittel wie Marmelade waren gänzlich verboten. Nach dieser Zeit zeigten 26/41 (63\%) der Patienten eine deutliche Verbesserung der Symptome

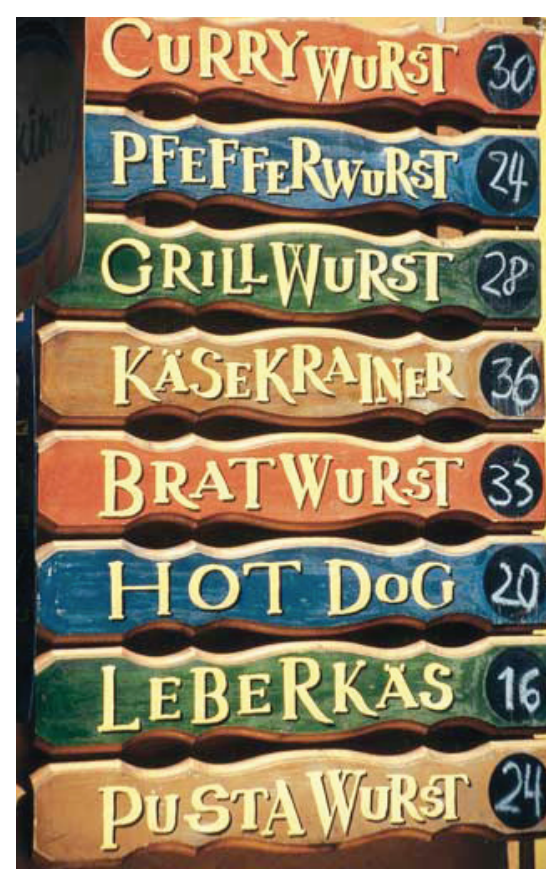

Verschlimmern Nahrungsmittelzusätze das atopische Ekzem?

(>35\% Änderung des Costa-Wertes): Der mittlere Costa-Wert dieser „Responder“-Gruppe fiel signifikant. $15 \mathrm{~Pa}$ tienten zeigten keine Besserung.

Um die Verursachung der AD durch Nahrungsmittelzusätze direkt nachzuweisen, wurden in der 3. Phase 24 Responder und 10 Non-Responder einer 2-tägigen Provokation mit Pseudo-allergen-reicher (PAR) Nahrung ausgesetzt. 19/24 Responder zeigten eine Verschlechterung der Symptome nach PAR-Nahrung. Die Reaktionen traten verzögert, meist erst nach 24 Stunden auf. Keiner der NonResponder zeigte eine besondere Reaktion auf PAR-Nahrung. Nach einer 2- tägigen Beruhigungsphase erhielten 15/19 Responder, die auf PARNahrung reagiert hatten sowie 10 NonResponder doppelblind und plazebokontrolliert eine Kapsel mit 23 gängigen Nahrungsmittelzusätzen. Nur 6/15 zeigten eine Verschlechterung, 1/10 Patienten zeigte eine Reaktion auf Plazebo.

Die klinische Diagnostik wurde durch eine serologische Analyse des eosinophilen kationischen Proteins (ECP) ergänzt. ECP, ein Entzündungsmediator, korreliert mit den klinischen Symptomen der AD. In Folge der Diät fielen die Serum-Konzentrationen von ECP bei 23/26 der Responder-Gruppe um durchschnittlich 52\%. Drei Responder zeigten eine Verbesserung der Symptome ohne Änderung von ECP. Die Non-Responder zeigten keine Änderung von ECP. Bei keinem Patienten wurde eine Änderung des Serum-IgE während der Diät beobachtet. Leider beschränkte sich die Serum Diagnostik auf Phase I und II und wurde nicht mehr nach der Provokationsstudie durchgeführt.

Die Autoren vermuten, dass der überwiegende Effekt der Pseudo-allergen-armen Diät in Wirklichkeit nicht auf der Hypersensitivität gegenüber Nahrungsmittelzusätzen, sondern auf unerkannten Typ-I-Allergien beruhen könnte. Bei ca. $80 \%$ der Testpersonen lag nämlich zusätzlich eine Pollenassoziierte Typ-I-Nahrungsmittelallergie vor. Insbesondere könnte eine oft unerkannte Kreuz-Reaktivität zwischen Beifuß- Pollen, Kräutern und Gewürzen zur Verbesserung der AD nach der Diät beigetragen haben.

Fazit: Die vorliegende Studie zeigt, dass eine entsprechende zusatzfreie Diät bei 63\% der Erwachsenen mit AD zu einer deutlichen Verbesserung der Symptome führt. Die Ergebnisse deuten auf eine Beteiligung von Nahrungsmittelzusätzen an der $\mathrm{AD}$ - allerdings konnte ein direkter Zusammenhang nicht eindeutig nachgewiesen werden.

\section{Worm $M$ et al.}

Clinical relevance of food additives in adult patients with atopic dermatitis. Clin Exp Allergy 2000; 30: 407-14. 